\section{Phonemic Awareness}

Deborah Witsken $^{1}$ and Dan Koonce ${ }^{2}$

${ }^{1}$ University of Minnesota Medical School, Minneapolis, MN, USA

${ }^{2}$ The Chicago School of Psychology, Chicago, IL, USA

\section{Definition}

Phonemic awareness is the ability to hear, identify, and manipulate individual sounds, or phonemes, in spoken words. The term is often confused with phonological awareness, which refers to a broader skill set involving manipulation of a wider range of sounds. Phonemic awareness involves understanding that spoken words are composed of unique sequences of individual speech sounds (Yopp 1992). Impairment in phonemic awareness has been linked to difficulties processing frequency cues or temporal encoding within the auditory system (Fitch et al. 1997). Activities measuring phonemic awareness often include letter sound fluency, sound isolation, blending sounds to form words, or segmenting words into smaller units (e.g., isolating first and last sounds). Although controversy persists, phonemic awareness has been pinpointed as a predictor of early reading success (NICHD 2000).

\section{Cross-References}

Educational Testing

- Letter Knowledge

- Phonics

- Reading

- Reading Comprehension

$\checkmark$ Reading Fluency

\section{References and Readings}

Fitch, H. R., Miller, S., \& Tallal, P. (1997). Neurobiology of speech perception. Annual Review of Neuroscience, 20, 331-335.

National Institute of Child Health and Human Development. (2000). Report of the National Reading Panel. Teaching children to read: An evidence-based assessment of the scientific research literature on reading and its implications for reading instruction (NIH publication no. 00-4769). Washington, DC: U.S. Government Printing Office.

Yopp, H. K. (1992). Developing phonemic awareness in young children. Reading Teacher, 45(9), 696-703. 